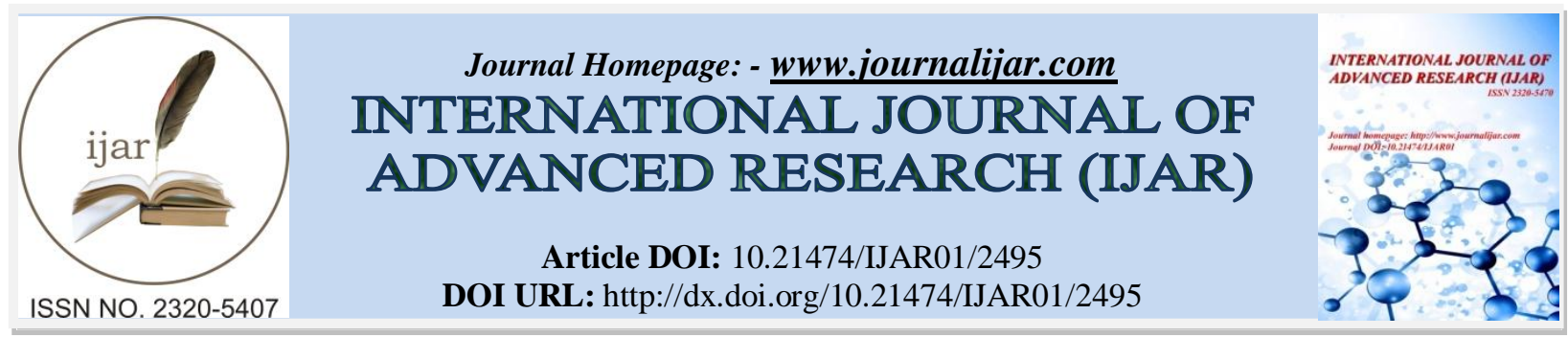

RESEARCH ARTICLE

\title{
COOPERATIVE LEARNING BETWEEN MEDICAL STUDENTS AND ITS EFFECTS ON EDUCATIONAL ATTAINMENT.
}

Osamah AbdulAziz Aldayel.

\section{Manuscript Info}

\section{Manuscript History}

Received: 25 October 2016

Final Accepted: 23 November 2016

Published: December 2016

Key words:-

Family medicine, Community medicine, Public health, Cooperative learning, AL-Imam Muhammad bin Saud Islamic University, medicine, Riyadh, Saudi Arabia.

\section{Abstract}

Background: Cooperative learning (CL) is refers to students working in teams ( group work) that minimizes the occurrence of Lack of understanding to understand topics and reduce unpleasant situations and satisfaction to learning. The present work is aimed at studying Medical Students Cooperative Learning and its Effects on Educational Attainment At al- Imam Mohammed bin Saud University College of Medicine in the Riyadh region, Saudi Arabia, toward CL .

Material and Methods: In this Cross-Sectional Study (Observational Survey), a simple random sample was taken from al- Imam Mohammed bin Saud University College of Medicine in Riyadh city. Data were collected through a self-administered questionnaire, from first year, second year, and third year. We used the SPSS program for data analysis.

Results: Of the participants, $36.3 \%$ had use cooperative learning. $(32.1 \%)$ of them their GPA is $3.5-4$. (25\%) of them is 4-4.5, $(21.4 \%)$ of them is $3-3.5, \quad(17.8 \%)$ of them is $4.5-5$ and $(3.5 \%)$ of them is lower than 3 . Of the participants, $63.7 \%$ they study alone. $(34.6 \%)$ of them their GPA is $3.5-4$. ( $22 \%$ ) of them is 4-4.5, (20.4 $\%)$ of them is $3-3.5,(16.3 \%)$ of them is $4.5-5$ and $(6.1 \%)$ of them is lower than 3. Motives which made grope cooperative study are $(39.2 \%)$ his member group have good GPA, (32.1\%) his member have same GPA and $(14.2 \%)$ are friends and study on exam time. Of the participant $(72.7 \%$ ) live with family. ( $41 \%$ ) of them has used CL. (45\%) of participant that live alone has used CL. Of participants that use CL , ( $46.4 \%$ ) consume 1-2 hours for studying. (32.1\%) consume $3-4$ hours and $(21.4 \%$ ) consume more than 4 hours. Of participants who study alone , ( $63.2 \%$ consume $1-2$ hours, $(28.5 \%$ ) consume 3-4 hours and $(8.1 \%)$ consume more than 4 hours.

Conclusion: most of medical students in AL-Imam University do not use $\mathrm{CL}$ in studying. The main motivation tend student to make CL group is goodness of GPA. Also, most of students who live alone are tend to CL more than they live with their families. In addition, most of student who study alone consume less time for studying than who use CL.

Copy Right, IJAR, 2016,. All rights reserved. 


\section{Introduction:-}

Cooperative learning (CL) is widely used In the world. A large and rapidly growing body of research confirms the effectiveness of cooperative learning in higher education Especially here in Saudi Arabia Because of medical colleges directed toward cooperative education Specifically on the point, the University of Imam Muhammad bin Saud Islamic, College of Medicine, used Cooperative Learning . Relative to students taught And study traditionally-i.e., with instructor-centered lectures, individual assignments, and competitive gradingcooperatively taught students tend to exhibit higher academic achievement, greater persistence through graduation, better high-level reasoning and critical thinking skills, deeper understanding of learned material, greater time on task and less disruptive behavior in class, lower levels of anxiety and stress, greater intrinsic motivation to learn and achieve, greater ability to view situations from others' perspectives, more positive and supportive relationships with peers, more positive attitudes toward subject areas, and higher self-esteem. There are several reasons why cooperative learning works as well as it does. The idea that students learn more by doing something active than by simply watching and listening has long been known to both cognitive psychologists and effective teachers and cooperative learning is by its nature an active method. Beyond that, cooperation enhances learning in several ways. Weak students working individually are likely to give up when they get stuck; working cooperatively, they keep going. Strong students faced with the task of explaining and clarifying material to weaker students often find gaps in their own understanding and fill them in. Students working alone may tend to delay completing assignments or skip them altogether, but when they know that others are counting on them, they are motivated to do the work in a timely manner.

\section{Objectives:-}

1) To measure the percentage of medical student that they cooperate.

2) To measure the effect of cooperative learning on GPA.

3) To determine motive which made grope cooperative study.

4) To compare capability of students outside and inside city to cooperative study.

5) To compare the time consume between cooperative study and individual study.

\section{Literature Review:-}

\section{Collaborative Learning Enhances Critical Thinking:-}

Research Questions:-

The research questions examined in this study were:

1. Will there be a significant difference in achievement on a test comprised of "drill-and practice" items between students learning individually and students learning collaboratively?

2. Will there be a significant difference in achievement on a test comprised of "critical-thinking" items between students learning individually and students learning collaboratively?

\section{Findings:-}

**It was found that students who participated in collaborative learning had performed significantly better on the critical- thinking test than students who studied individually.

** It was also found that both groups did equally well on the drill- and- practice test. This result is in agreement with the learning theories proposed by proponents of collaborative learning.

**Students are capable of performing at higher intellectual levels when asked to work in collaborative situations than when asked to work individually.

**Group diversity in terms of knowledge and experience contributes positively to the learning process

**Cooperative learning methods improve problem- solving strategies because the students are confronted with different interpretations of the given situation.

**The peer support system makes it possible for the learner to internalize both external knowledge and critical thinking skills and to convert them into tools for intellectual functioning. 


\section{Conclusion:-}

Collaborative learning fosters the development of critical thinking through discussion, clarification of ideas, and evaluation of others' ideas. However, both methods of instruction were found to be equally effective in gaining factual knowledge, Therefore, if the purpose of instruction is to enhance critical- thinking and problem- solving skills, then collaborative learning is more beneficial.

\section{Researcher:-}

Anuradha A. Gokhale is an Associate Professor at Western Illinois University in the Department of Industrial Education and Technology, and is currently a Visiting Associate Professor at Illinois State University.

\section{The Effect of Cooperative Education on Change inSelf-Efficacy:-}

By: JosePh a. raelinNortheastern University margaret B. BaileY Rochester Institute of Technology JerrYhamann University of Wyoming Jonathan d. raelinUniversity of Bath rachellereisBergNortheastern University daVidwhitman University of Wyoming leslie K. Pendleton Virginia Polytechnic Institute and State University.

\section{Objectives:-}

1. The determination of self-efficacy

2. effect of cooperative education on self-efficacy

3. whether the quality of the co-op placement accounts for self-efficacy enhancement.

\section{Main finding:-}

Self-efficacy is defined as an individual's perceived level of competence or the degree to which she or he feels capableof completing a task.

This study examines the effect of cooperative education, controlling for contextual support and demographic characteristics, on three dimensions of self-efficacy change: work, career, and academic. Of the three forms of selfefficacy, work self-efficacy was found to be the one efficacy form impacted by cooperative education. Since selfefficacy is shaped by performance accomplishments, student success in their co-op jobs appears to enhance their confidence in performing a variety of behaviors that are particular to handling the requirements of the workplace. Change in work self-efficacy was also affected by change in students' confidence in their career orientation.

\section{Conclusion:-}

Relationship Between Cooperative Education and Self-Efficacy Change.

As could be expected, the overall support co-op students experienced during their time on co-op decreased; in particular, support available from their collegiate advisor. Interestingly, co-op students' GPAs did not decrease as much as non-co-op students' GPAs.

Can be concluded that students on internships are more likely to experience a positive change in their career selfefficacy compared to students choosing neither co-ops nor internships. Besides change in career self-efficacy, there appears to be a likelihood that interns are also more involved in campus life and feel more supported by their university, although these results, Relationship between co-op quality and subsequent self-efficacy, three co-op quality dimensions were found to be significant predictors. The most potent predictor was whether the co-op placement made a difference to the unit or organization employing the student. The second was whether the placement allowed the student to be part of a team, and the third was whether the placement applied knowledge in the student's major Cooperative Learning and the Social Nature of Learning by Aaron Burdon.

\section{Research Questions:-}

What Is Cooperative Learning?

what is Advantages and Possible Challenges of Cooperative Learning?

\section{Objective:-}

Definition of Cooperative learning

Advantages and Possible Challenges of Cooperative Learning

Conclusion

What Is Cooperative Learning? 
The traditional classroom often consists of classes in which children of similar ability levels are taught together. Nearly all classrooms in the United States are taught by grade level specific to the age of the student rather than his or her ability. Many schools also group students according to their apparent ability levels, but this risks becoming a self-fulfilling prophecy for each respective group. By placing students into group in this way, we run the risk of those placed in low-level learning groups perceiving themselves as unintelligent or slow-witted. Grouping students together with varying levels of ability and backgrounds can help eliminate this threat. A very popular method of learning in this way is called cooperative

Cooperative learning is defined as "the collaboration on a task by a small group of students who resolve differences of opinion, share responsibility, consider one another's ideas, and work toward common goals." (Berk, 2008) Unlike traditional methods, cooperative learning lets students enhance the weaknesses of their peers with their own strengths. Students feel a part of a team rather than isolated and students deemed as having low-ability can benefit from those considered higher. In a symbiotic relation, higher level students also tend to do better by teaching the learned material to their peers.

According to Robert E. Slavin of Johns Hopkins University, there are four major perspectives on cooperative learning, which are motivational, social cohesion, cognitive development, and cognitive elaboration (Slavin, 1995). The motivational perspective focuses on the reward for the group in achieving their objective, and that the only way for the group to achieve this goal is to learn how to work together. The theory that students want each other to succeed is more in keeping with the social

cohesion perspective, but is similar to the motivational perspective in that the members of the group are motivated to succeed, but instead of goal oriented, it is

The cognitive development perspective takes a very different approach to cooperative learning in that it contends that the interaction of students with their peers stimulates the mind and increases the ability to learn. Unlike being motivated by a common goal or by compassion for their peers, those who follow the cognitive development perspective feel that the human brain simply learns better in a group environment than on its own.

A variation of this is the fourth theory of cognitive elaboration, which contends that the best way to enhance the knowledge already present in the brain is to in turn explain it to ones peers. This slightly differs from cognitive development perspective in that the members of the group must already have some knowledge of the material before entering the group.

\section{Conclusion:}

In conclusion, cooperative learning is a very different style of learning than how traditional school systems have taught student. There are a number of theories behind why this method tends to be effective; however, there are still a number of unknown variables out there that make cooperative learning hardly the absolute best way to present material. Still, learning methods like Kagan's RoundRobin and Aronson's Jigsaw techniques have proven to be very helpful and have empirical evidence that supports the increase in participants learning ability.

The relationship between the quality of cooperative learning, students' goal preferences, and perceptions of contextual factors in the classroom.

\section{objective:-}

This paper reports a study into the relationship between motivational processes, contextual factors and the quality of cooperative learning (CL) processes of adolescent students in secondary vocational education in the Netherlands.

We view motivational processes as an intricate part of the students' self-regulation process, namely that part that is steered by their values and goal preferences. It is generally assumed that students steer their behavior in the direction of valued goals and away from non-valued goals (Boekaerts, Pintrich \& Zeidner,

2000).

\section{Main finding:-}

- we predicted that belongingness, social support and mastery goals would be positively relatively and superiority/ individuality goal preferences negatively related to the quality of CL. 
- We assumed that in order for students to cooperate well it is very important that they know how to cooperate in the first place. In other words, we assumed that the quality of CL will be poor when students indicate that they were not taught the necessary skills.

- we explored gender and program type effects on the relationship between students' goal preferences and the quality of CL.

\section{Conclusion:-}

This study examined relationships between the quality of cooperative learning (CL) and students' goal preferences and perceptions of contextual factors in the classroom. Subjects were 1,920 students in secondary vocational schools. The study focused on four different types of goals:

social support, belongingness, mastery, and superiority goals. It was found that social support goals had the strongest relation with the quality of CL. Further we found that the quality of CL was best predicted by a combination of social support goals, evaluations of the extent that students were taught cooperation skills, perception of teacher monitoring behavior, and the availability of academic and emotional peer support. Female students' preferences for mastery and social goals were stronger than those of male students, whereas male students had a stronger preference for superiority goals. Program type functioned as a moderator variable within the relation of students' superiority/ individuality goals and the quality of CL.

\section{Researcher:-}

Daphne hijzen, monique boekaerts and paul vedder Leiden University, the Netherlands Enhancing student achievement through cooperative learning at the elementary level by Briana L. Bancroft.

\section{Objective:-}

Elementary schools best utilize cooperative learning to increase achievement levels..

Positive Interdependence - occurs when gains of individuals or teams are positively correlated.

Equal Participation - occurs when each member of the group is afforded equal shares of responsibility and input Simultaneous Interaction - occurs when class time is designed to allow many student interactions during the period

\section{Main finding:-}

All of these studies showed different aspects of cooperative learning, but all show how valuable it can be. Students at the elementary level would gain a rich base of academic and social learning that they could call on for the rest of their educational and professional careers. If certain characteristics of all the studies were merged, the union could result in a tremendous program for any building or district looking to transform their curriculum and school community.

\section{Conclusion:-}

The cooperative style of learning makes students work toward a common goal, and succeed as a group where as each member is an integral part. The study performed by Stevens and Slavin (1995) showed that students showed increased social relations across the two-year time frame. Imagine the effect after four or six. This kind of school atmosphere would foster an environment where all students are looked at as an essential part of the learning community.

\section{Material And Methods:-}

Cross-Sectional Study (Observational Survey), a simple random sample was taken from al- Imam Mohammed bin Saud University College of Medicine in Riyadh city. Data were collected from 77 participants through a selfadministered questionnaire, from first year, second year, and third year. We used the SPSS program for data analysis.

\section{Background:-}

Imam Muhammad Ibn Saud Islamic University in Riyadh, Saudi Arabia, was founded in 1953.In 1974, it was granted university status by royal decree. The university houses 14 faculties. It currently has more than 28,000 students and 1,850 faculty. It has intermediate and secondary Islamic institutes in major cities of Saudi Arabia, Ras al-Khaimah, the USA, Indonesia, Malaysia, Djibouti and Japan. The university as a cultural and intellectual 
institution aims to promote knowledge offering undergraduate as well as postgraduate studies. One of the most important aims is to promote translating and publishing as the university has its own print house. Moreover, the university achieves its goals within the Islamic Shari'a.

\section{Results:-}

Of the participants, $36.3 \%$ had use cooperative learning (CL ). \{ Figure 1$\}.$.

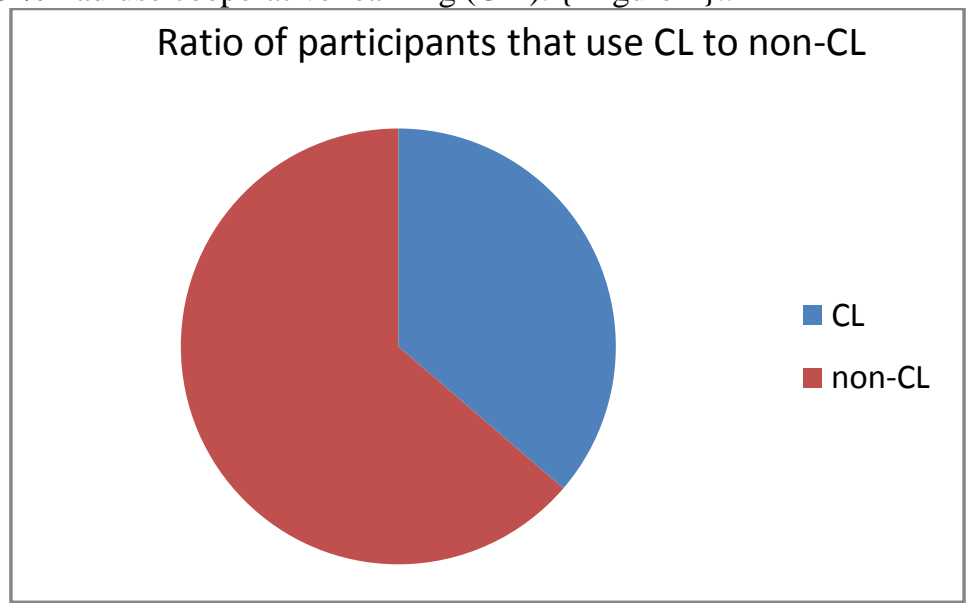

\section{Figure 1:-}

$(32.1 \%)$ of them their GPA is $3.5-4$. ( $25 \%$ )of them is $4-4.5,(21.4 \%)$ of them is $3-3.5, \quad(17.8 \%)$. of them is 4.5-5 and $(3.5 \%)$ of them is lower than 3 . Of the participants, $63.7 \%$ they study alone. $(34.6 \%)$ of them their GPA is $3.5-4$. (22\%) )of them is 4-4.5, (20.4\%) of them is 3-3.5, (16.3\%) of them is 4.5-5 and $(6.1 \%)$ of them is lower than 3. \{ Figure 2\} .. Motives which made grope cooperative study are (39.2\%) his member group have good GPA, $(32.1 \%)$ his member have same of GPA and (14.2\%) are friends and study on exam time \{ Figure 3 \}. Of the participant $(72.7 \%)$ live with family. ( $41 \%$ ) of them has use CL. (45\%) of participant that live alone has used CL. \{ Figure 4 \}.. Of participants that use CL, ( $46.4 \%$ ) consume 1-2 hours for studying. (32.1\%) consume 34 hours and $(21.4 \%)$ consume more than 4 hours. Of participants who study alone , ( $63.2 \% 0$ consume 1-2 hours, $(28.5 \%)$ consume $3-4$ hours and $(8.1 \%)$ consume more than 4 hours. \{Figure 5 \}

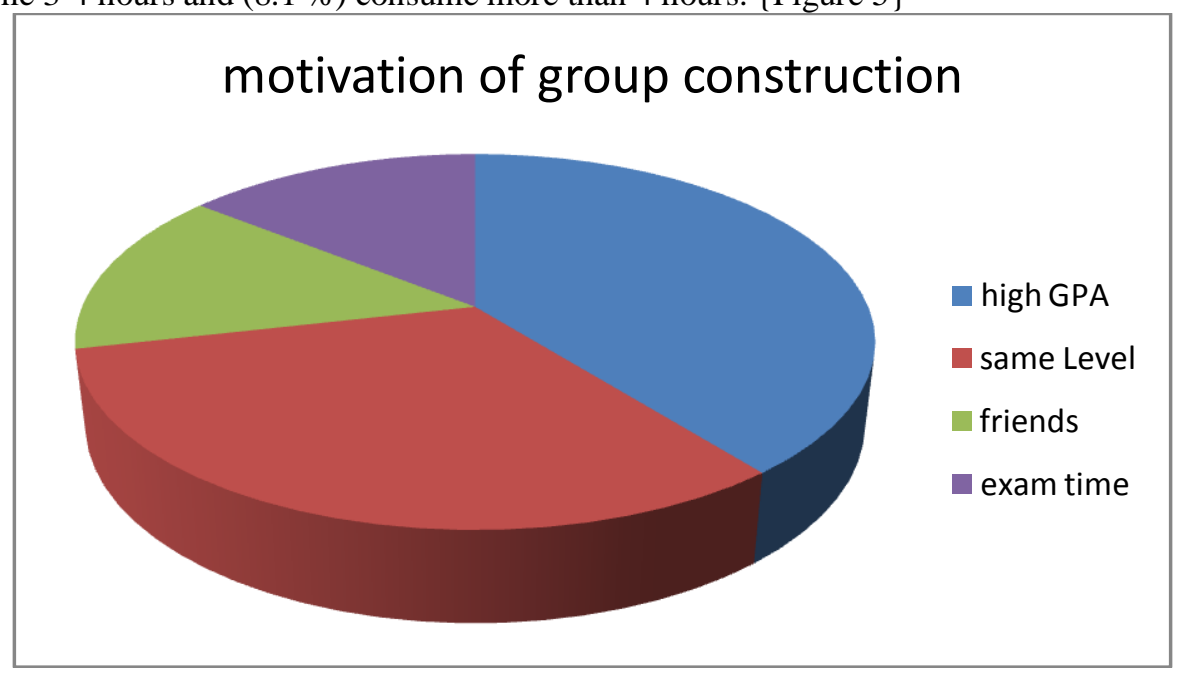

Figure 2:- No. of students Students' GPA 


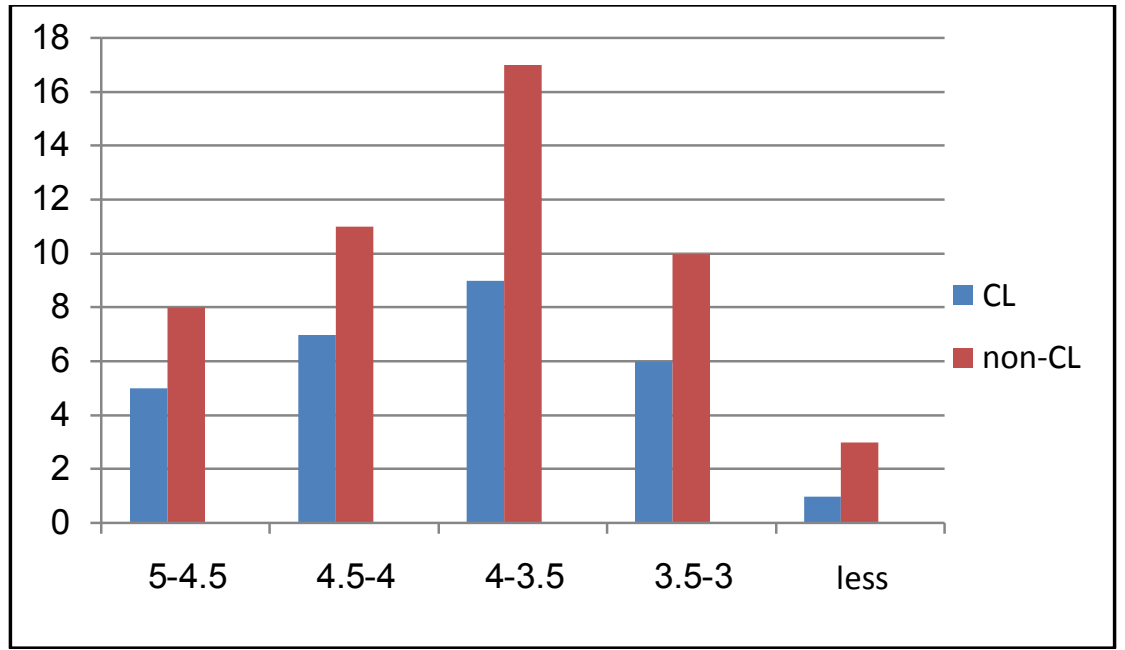

Figure 3:-

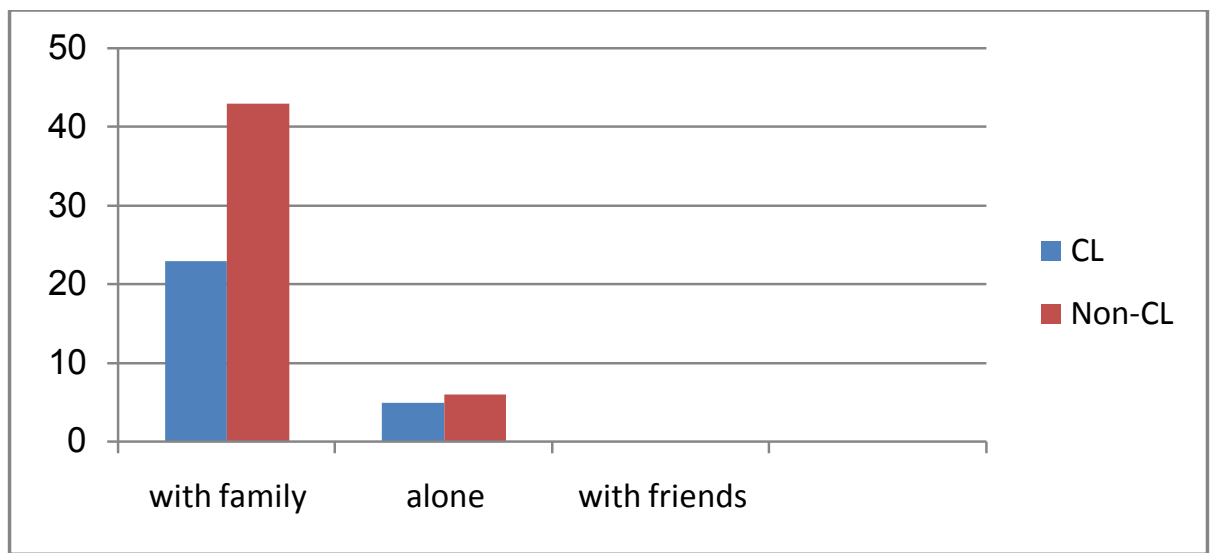

Figure 4:- NO. Of Students Students living

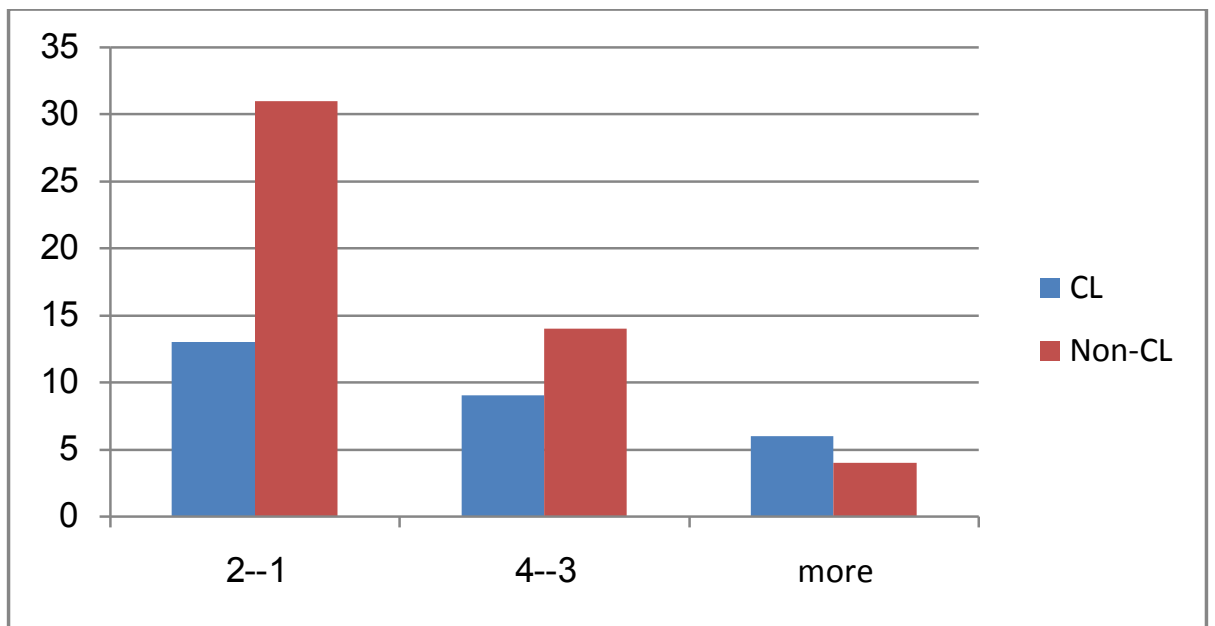

Figure 5 No. of students Time consumed

\section{Discussion:-}

Results of the present study showed (36.3\%) had use CL major of them has GPA 3,5-4. On other side, these who do not use CL (34.6\%) has GPA 3,5-4. It is not indicate to big deal. But 3,1\% from student use CL them GPA less 
than 3, while $6.1 \%$ from student do not use CL them GPA less than 3. Also, Motives which made grope cooperative study are his member group have good GPA. This study showed student who live alone tend to study with group more than student live with them family. Furthermore, Most of the students who use CL or do not use spend $1-2$ hours for study. In contrast, the student who use CL The proportion of a few of them spend more than 4 hours.

From this study we can see the students who live alone Prefer to use CL and formed group on the basis of members have good GPA. The most of medical students in AL-Imam University do not use CL in studying.

\section{Conclusion:-}

most of medical students in AL-Imam University do not use CL in studying. The main motivation tend student to make CL group is goodness of GPA. Also, most of students who live alone are tend to CL more than they live with their families. In addition, most of student who study alone consume less time for studying than who use CL.

\section{Recommendation:-}

We recommend that:-

1. Promote the concept of cooperative learning in the college of Medicine at Imam Muhammad bin Saud University to reduce the decline of GPA.

2. Add some lectures for students to explain the methods of selection groups study.

3. Enhance the college environment to help students on cooperative learning.

4. Faculty staff members Should assign students to work on group .

5. We should make another study to find out why most of students do not desire to study in cooperative manner 